\title{
Esporte, técnica e juventude: notas sobre a antropologia filosófica de José Ortega y Gasset
}

\author{
Jaison José Bassani ${ }^{1}$ \\ Alexandre Fernandez $\mathrm{Vaz}^{2}$ \\ ${ }^{1}$ Departamento de Educação Física e do Programa de Pós-graduação em Educação \\ Física da Universidade Federal de Santa Catarina, Florianópolis, SC, Brasil; Membro do \\ Núcleo de Estudos e Pesquisa Educação e Sociedade Contemporânea (UFSC/CNPq) \\ 2 Programas de Pós-graduação em Educação e Interdisciplinar em Ciências Humanas da \\ Universidade Federal de Santa Catarina, Florianópolis, SC, Brasil; Coordenador do \\ Núcleo de Estudos e Pesquisas Educação e Sociedade Contemporânea (UFSC/CNPq) e \\ Pesquisador CNPq - Fundamentos da Educação.
}

\begin{abstract}
Resumo: Trata o presente de uma investigação sobre o tema do esporte na obra do filósofo espanhol José Ortega y Gasset, tendo como fontes principais os doze volumes que compõem as Obras Completas do autor. Os resultados, expostos e discutidos a partir de três categorias articuladoras, revelam que o esporte, em articulação com a técnica e a juventude, temas que frequentemente aparecem inscritos no mesmo nexo interpretativo em Ortega, pode ser lido no contexto de sua obra como uma espécie de metáfora significadora do caráter lúdico e não-utilitarista da vida humana, interpretação em conformidade com as grandes questões que delineiam o núcleo central do arcabouço filosófico orteguiano. Conclui-se destacando o pioneirismo das análises de Ortega sobre o nascente processo de expansão do esporte e sua crescente importância social nas primeiras décadas do século XX, assim como a necessidade de se considerar a juventude como problemática filosófica e sociológica.
\end{abstract}

Palavras-chave: Esporte. Antropologia filosófica. Ortega y Gasset. José.

\section{Sport, Technique and Youth: Appointments on José Ortega y Gasset's Philosophical Anthropology}

Abstract: This paper presents results of a research whose aim was to investigate sport by the Spanish Philosopher José Ortega y Gasset. The sources are the twelve volumes of his Complete Writings. The results are exposed by three conceptual keys, and suggest that sport, linked to technique and youth, parts of the same reflection by Ortega, can be understood as a metaphor of the non utilitarian character of human life, an important theme of Ortega's Philosophy. The Avant Gard character of Ortega's Analysis about the Expansion of Sport in the first decades of Twentieth Century is underlined, as well as youth as philosophical and sociological subject.

Key Words: Sport. Philosophical Antropology. Ortega y Gasset. José.

\section{Introdução}

O filósofo e pensador espanhol José Ortega y Gasset (1883-1955) foi um homme de lettres que fez da premissa de pensar o seu tempo, o tempo presente, tarefa e projeto intelectual. Essa preocupação, a de estar à altura dos tempos, se revela, entre outros aspectos, e para além do desenvolvimento de sua obra mais especificamente filosófica, no engajamento na vida pública - Ortega foi deputado da província de León durante a chamada Segunda República Espanhola - e na importância atribuída ao papel de formação e de direção político-cultural exercido pela opinião pública, especialmente da intelligentsia européia.

É em parte por conta dessa compreensão que Ortega y Gasset possuía sobre a atuação e o papel do intelectual na sociedade, aliado ao clima cultural da Europa daquela época, particularmente da Espanha, que grande parte de seus escritos foi publicada originalmente em importantes jornais na Espanha e em outros tantos países por onde morou, como, por exemplo, a Argentina. Ele foi não apenas colaborador, mas também fundador de diversos tablóides e revistas, como por exemplo, o jornal Faro e a famosa Revista de Occidente. Apesar de Ortega também ter divulgado vários de seus trabalhos em revistas, publicações especializadas e livros, a imprensa diária e, secundariamente, as aulas ministradas como catedrático de Metafísica da Universidade Central de Madri e as conferências e atividades culturais extra-acadêmicas proferidas em diversos países, constituíam a principal forma de comunicação com seu público. Outro motivo que 
é preciso considerar na preferência do autor pelo texto jornalístico, certamente um meio pouco usual entre os filósofos europeus da época, está relacionado a ter sido ele não apenas um filósofo, mas também, e em importante medida, um escritor de grande expressão na Espanha e, em geral, no mundo de língua hispânica (MORA, 1973, p. 27-34).

É enorme a quantidade e variedade de temas sobre os quais o autor madrilenho escreveu e se dedicou a pensar. Uma rápida olhada no índice dos doze volumes de suas Obras Completas confirma a multiplicidade de interesses desse extraordinário pensador e ensaísta: críticas e escritos sobre música, pintura, teatro, arquitetura; discursos políticos; conferências pronunciadas intra e extramuros universitários e em diversos países; interpretações sociológicas e antropológicas; prefácios e comentários de dezenas de obras cuja tradução para o espanhol organizou como diretor da coleção Biblioteca de las ideas del siglo $X X$; textos sobre educação e pedagogia; interpretações e ensaios filosóficos, entre tantos outros.

Dentre os temas aos quais Ortega se dedicou, figura também o esporte, compreendido por ele a partir de um prisma que poderíamos denominar de antropológico-filosófico. No presente trabalho, objetivamos mostrar que, embora não se possa afirmar, dada, inclusive, a reduzida dimensão do corpus teórico sobre o assunto, se considerado os doze volumes de suas Obras Completas, que Ortega realizou uma antropologia ou sociologia do esporte, não se deve, no entanto, menosprezar a relevância que a temática adquire ao longo de sua obra. Apesar de ter empreendido esforços, ainda que em menor medida, para compreender a crescente importância social do desenvolvimento esportivo no começo do século $X X$, o escopo principal das reflexões de Ortega sobre o esporte, como procuraremos mostrar na sequência, perece residir na exposição dos pressupostos antropológicos que possibilitam compreendê-lo, assim como a outras manifestações lúdicoexpressivas, símbolos do desejo e da capacidade criadora do ser humano, cuja vida é um projeto extranatural concebido e fabricado por ele.

Nas próximas páginas, após descrever os procedimentos metodológicos e localizar o conjunto de fontes analisadas, buscamos mostrar que o esporte, em articulação com os temas da técnica e da juventude, que frequentemente aparecem inscritos no mesmo nexo interpretativo em Ortega, pode ser lido no contexto da obra do autor como uma espécie de metáfora significadora do caráter lúdico e não-utilitarista da vida humana, interpretação que, de acordo com nossa análise, está em conformidade com as grandes questões que delineiam o núcleo central do arcabouço filosófico orteguiano.

\section{Metodologia e Fontes}

O material principal de análise do presente trabalho adveio dos doze volumes que compõem as Obras Completas de Ortega y Gasset. ${ }^{1}$ Nosso esforço não consistiu apenas em localizar os comentários ocasionais do autor sobre o esporte espalhados ao longo desses escritos, senão em interpretá-los à luz dos grandes temas que compõem o núcleo central sua obra mais especificamente filosófica, de caráter mais sistemático. Embora nossa preocupação central recaísse em pensar o tema do esporte como possível chave de leitura da interpretação que Ortega empreende dos fundamentos ontológicos da vida humana, não nos ocupamos somente dos textos nos quais o autor trata exclusivamente do tema. A perspectiva foi, como anunciado acima, buscar no seu corpus teórico o lastro mais amplo no qual a problemática do esporte pudesse ser analisada.

Para fins de exposição e discussão dos resultados encontrados, organizamos o texto na sequência a partir de três categorias articuladoras, a saber: 1) A vida como um jogo luxuoso, onde buscamos destacar a interpretação de Ortega sobre o caráter "esportivo" da vida humana; 2) Esporte, técnica e aristocracia, no interior da qual se busca mostrar que o significado metafórico do esporte na obra de Ortega também se vincula à importância atribuída pelo autor à dimensão "aristocrática" da existência, a qual é possibilitada, em grande medida, pela técnica; e 3) Corpo, juventude e esporte, que corresponde às reflexões de Ortega sobre a transformação do esporte em espetáculo de massa - e sua consequente "desaristocratização" - na alvorada do século $X X$.

\section{Resultados e análises A vida como um jogo luxuoso}

O tema do esporte aparece na obra de Ortega y Gasset, geralmente, sob a forma de notas esparsas e comentários ocasionais. ${ }^{2}$ Ainda que se

\footnotetext{
1 As menções aos trabalhos de Ortega, salvo exceções devidamente indicadas, referem-se às Obras Completas do autor (ORTEGA Y GASSET, 1983a), editada em doze volumes e publicadas em 1983 pela Alianza Editorial e pela Revista de Occidente, ambas de Madri.

2 Veja-se, por exemplo: Revés de almanaque (ORTEGA Y GASSET, 1983b, p. 719-742); Conversación en el "golf" o la idea del "dharma" (ORTEGA Y GASSET, 1983b, p. 403-409); El deporte de los ideales (ORTEGA Y GASSET, 1983b, $p$. 434-439); El tema de nuestro tiempo, especialmente os capítulos VIII (Valores vitales), IX (Nuevos síntomas) e X (La doctrina del punto de vista) (ORTEGA Y GASSET, 1983c, $p$.
} 
possa destacar, como fez Bolaño (2008), a importância de $O$ que é filosofia? para a construção de uma "filosofia do esporte", provavelmente o mais importante e conhecido ensaio no qual Ortega se debruça sobre a temática, a grande exceção de sua obra, é certamente El origen deportivo del Estado, escrito em 1924 e publicado em 1930 no sétimo volume de El Espectador (ORTEGA Y GASSET, 1983b, p. 607-623). Nele vemos Ortega defender a ideia, conforme sugere o próprio título, de que o esporte é o fator primordial e originário do surgimento do Estado. Não é nosso propósito aqui discutir detalhadamente as minúcias dos argumentos que permitem a Ortega "rastrear" a gênese histórica $e$ irracional (ORTEGA Y GASSET, 1983b, p. 618) da sociedade e do Estado, mas, sobretudo, extrair o núcleo central da tese por ele defendida, qual seja, de que as manifestações lúdico-expressivas, das quais se destaca o esporte, representam as atividades realmente fundantes da agência humana.

A partir de uma interpretação, por ele mesmo classificada, em oposição à "verdade científica", como reconstrução mitológica ${ }^{3}$, Ortega distingue duas explicações para o que considera ser uma das grandes questões da humanidade: a ideia ou a representação que possuímos da vida. Para o filósofo espanhol, a enorme propensão ao utilitarismo do século XIX não poupou o fenômeno vital. Segundo ela, a atividade primária da vida consistiria em responder a exigências iniludíveis e à satisfação de necessidades impreteríveis. Em uma palavra: a vida, em todas as suas manifestações, seria um fenômeno de utilidade e adaptação. (ORTEGA Y GASSET, 1983b, p. 608609). No entanto, uma segunda concepção, concorrente dessa primeira, teria emergido, segundo Ortega, à luz das novas descobertas da biologia e do campo da historiografia de sua época, e possibilitaria compreender a vida de forma distinta, agora segundo a ideia de que "todos los actos utilitarios y adaptativos, todo lo que es reacción a premiosas necesidades, son vida secundaria. La actividad original y primera de

187-203); Dinámica del tiempo (ORTEGA Y GASSET, 1983c, p. 459-480);

${ }^{3}$ A segunda, diferentemente da primeira, capaz de oferecer uma paisagem apenas mutilada, fragmentada, responderia ao anseio humano por uma perspectiva integral, como primeiro $e$ último pano de fundo, como uma espécie de sistema cardeal para sanar nossa carência de orientação (ORTEGA Y GASSET, 1983b, p. 608). Nas palavras do autor: "La 'verdad científica' es una verdad exacta, pero incompleta y penúltima, que se integra forzosamente en otra especie de verdad, última y completa, aunque inexacta, a la cual no habría inconveniente en llamar 'mito'. La verdad científica flota, pues, en mitología, y la ciencia misma, como totalidad, es un mito, el admirable mito europeo." (ORTEGA Y GASSET, 1983b, $p$. 608). la vida es siempre espontánea, lujosa, de intención superflua, es libre expansión de una energía preexistente." (ORTEGA Y GASSET, 1983b, p. 609). ${ }^{4}$ A partir dessa interpretação, Ortega estabelece duas grandes classes para dispor os fenômenos orgânicos, tanto animais quanto humanos: ${ }^{5}$ uma atividade originária, criadora e vital por excelência, que seria, como dito, espontânea e desinteressada; e outra, que aproveitaria e mecanizaria a primeira, e que é de caráter eminentemente utilitário. Essa segunda classe de fenômenos não inventa, não cria nada, simplesmente emprega e estabiliza o que fora criado sem ela, sem o propósito inicial de utilidade. (ORTEGA Y GASSET, 1983b, p. 609). Uma terceira e igualmente dupla diferenciação emergiria dessas duas primeiras, uma vez que, embora a vida sempre nos apareça como um esforço, este é, para Ortega, de duas ordens: o esforço que fazemos pelo simples deleite de fazêlo, e aquele que uma necessidade imposta e não inventada por nós nos angustia e impele. $O$ exemplo máximo desse esforço obrigado, constrangedor, com o qual satisfazemos, de modo estrito, uma necessidade, é o trabalho, da mesma forma que a primeira classe de esforços, que Ortega chama de supérfluos, encontra seu exemplo mais eloquente no esporte. Seguindo esse raciocínio, Ortega concluirá pela necessidade de

[...] transmutar la inveterada jerarquía y considerar la actividad deportiva como la primaria y creadora, como la más elevada, seria e importante en la vida, y la actividad laboriosa como derivada de aquélla, como su mera decantación y precipitado. Es más: vida, propiamente hablando, es sólo la de cariz deportivo; lo otro es relativamente mecanización y mero funcionamiento. (ORTEGA Y GASSET, 1983b, p. 610).

A origem do Estado e, em última instância, da própria sociedade, representa um exemplo da fecundidade criadora contida na potência das atividades que chamaríamos, com Ortega, de supérfluas. Para o autor, o primeiro impulso de

\footnotetext{
${ }^{4}$ Um importante intérprete do Brasil e do futebol brasileiro caminha na mesma direção de Ortega. Roberto DaMatta também entende que o esporte não é uma decorrência necessária da utilidade e do trabalho, mas uma atividade que está carregada de caráter lúdico e expressivo: "O mundo não começou com os homens buscando comida e realizando guerras. O impulso primordial, se é que se pode realmente falar nisso, foi dado tanto pelo corpo quanto pelo espírito. Se me for permitido parafrasear Lévi-Strauss, diria que o primeiro dado não foi somente bom para matar, mas também para divertir, decorar e pensar." (DAMATTA, 1982, p. 24). A vinculação entre o impulso de dominação da natureza $e$ aquele que se encontraria no esporte pode ser encontrada, no entanto, em autores como Jürgen Habermas (1967) e Theodor W. Adorno (1997).

5 Semelhante classificação também é empregada por Ortega no ensaio Sobre la expresión, fenómeno cósmico (ORTEGA Y GASSET, 1983b, p. 581).
} 
associação, chamado por ele de instinto de coetaneidade (ORTEGA Y GASSET, 1983b, p. 614), que se dá justamente entre os jovens varões e do qual surge a primeira forma de organização social (a horda informe), é de origem esportiva. A partir de uma particular interpretação da história, que, como expressa o autor em outros trabalhos $^{6}$, avança segundo um duplo ritmo, o das idades e o dos sexos, ${ }^{7}$ e da generalização de um episódio mítico da fundação da cidade de Roma (o rapto das sabinas), Ortega dirá que a primeira sociedade humana é exatamente o contrário de uma reação a determinadas necessidades impostas. Ela surge da associação de jovens para raptar mulheres de hordas consanguíneas que Ihes fossem externas e realizar toda sorte de façanhas bárbaras:

[...] los muchachos de dos o tres hordas próximas, impulsados por ese instinto de sociabilidad coetánea, deciden juntarse, vivir en común. Claro es que no para permanecer inactivos: el joven es sociable, pero a la par es hazañoso, necesita acometer empresas. Indefectiblemente entre ellos surge un temperamento o más imaginativo, o más audaz, - más diestro, que propone la gran osadía. [...]Y entonces ha lugar una de las acciones más geniales de la historia humana, de que han irradiado más gigantescas consecuencias: deciden robar las mozas de hordas lejanas. Pero esto no es empresa suave: las hordas no toleran impunemente la sustracción de sus mujeres. Para robarlas hay que combatir, y nace la guerra como medio al servicio del amor. Pero la guerra suscita un jefe y requiere una disciplina: con la guerra que el amor inspiró

\footnotetext{
6 Sobre o tema conferir, entre outros, El tema de nuestro tiempo (ORTEGA Y GASSET, 1983c, especialmente p. 145162), La rebelión de las masas (ORTEGA Y GASSET, 1983d, especialmente p. 231-278).

7 Para Ortega, tanto nas sociedades arcaicas quanto nas de nossos dias, prevalece a idade e o sexo - e não a posição em relação aos meios de produção, como postula a tradição marxista - como princípios de organização social, de tal forma que teríamos as seguintes classes: homens maduros, jovens e velhos; varões e mulheres. A dinâmica histórica se dá, então, através da sucessão do predomínio de uma ou outra classe e sua capacidade para influenciar os acontecimentos. Assim como a vida é rítmica (de jovens tornamo-nos adultos e posteriormente velhos), também a história, diz Ortega - num tom bastante próximo do de Spengler $(1973 ; 2007)$-, segue o ritmo que é o da condição biológica. Dessa forma teríamos épocas em que predominaria o masculino, e outras em que se assenhoreiam os instintos de feminilidade; há épocas de predomínio juvenil e outras de predomínio dos velhos. Nas palavras de Ortega: "Masculinidad y feminilidad, juventud y senectud, son parejas de potencias antagónicas. Cada una de esas potencias significa la movilización de la vida toda en un sentido divergente del que lleva su contraria. Vienen a ser como estilos del vivir. Y como todos coexisten, en cualquier instante de la Historia, se produce entre ellos una colisión, un forcejeo en que intenta cada cual arrastrar en su dirección, íntegra, la existencia humana. Para comprender bien una época es preciso, pues, determinar la ecuación dinámica que en ella dan esas cuatro potencias y preguntarse: ¿Quién puede más? ¿Los jóvenes o los viejos (es decir, los hombres maduros)? ¿Lo varonil o lo femenino?" (ORTEGA Y GASSET, 1996, p. 209-210).
}

surge la autoridad, la ley y la estructura social [...]. (ORTEGA Y GASSET, 1983b, p. 616).

Fruto dessa empresa amorosa, a vida em comum e sob a autoridade de um chefe, destaca Ortega, inspira a ideia de construir um abrigo seguro e fixo. Esse albergue edificado pela horda juvenil não é a casa da família, ainda inexistente, mas sim o clube, o cassino dos jovens, onde se preparam para suas expedições, realizam rituais e se dedicam à atividades como cantar e beber, ao frenético banquete comum (ORTEGA $Y$ GASSET, 1983b, p. 616). Esse espaço, que Ortega afirma ser chamado pelos etnólogos de "casa dos solteiros", representa um tabu e, portanto, uma interdição para os demais membros da horda, como mulheres, crianças e homens maduros. É um lugar misterioso e secreto, marcado por uma férrea disciplina interna e pelo treinamento, onde se cultivam destrezas vitais tais como a caça e a guerra:

Es decir, que la asociación política originaria es la sociedad secreta y que si sirve para el placer y la bebida es, al propio tiempo, el lugar donde se ejercita el primer ascetismo religioso y atlético. Recuérdese que la más exacta traducción del vocablo ascetismo es "ejercicio de entrenamiento", y los monjes no han hecho sino tomarlo del vocabulario deportivo usado por los atletas griegos. "Askesis" era el régimen de vida del atleta, llena de ejercicios y privaciones. De donde resulta que el casino de los jóvenes, primera casa y primer "club" placentero, es también el primer cuartel y el primer convento. (ORTEGA Y GASSET, 1983b, p. 617).

Nesse sentido, conclui Ortega, não foi 0 trabalhador, nem o intelectual, ou o sacerdote propriamente dito, e tampouco o comerciante que iniciaram o processo político e a vida social. Foi a juventude guerreira e preocupada com a conquista amorosa; foi o clube de varões juvenis, espaço por excelência, como destacado anteriormente, de atividades não propriamente utilitárias, mas lúdicas, como as danças, os rituais com o uso de máscaras, a cantoria, a comezaina coletiva etc.; foram os jovens amadores, guerreiros e esportistas que deram origem ao Estado e à sociedade (ORTEGA Y GASSET, 1983b, p. 619). Não apenas a gênese, senão também todos os avanços da humanidade e das

\footnotetext{
8 Esse ímpeto amoroso, que é simultaneamente belicoso, o qual representa para Ortega o protótipo da vitalidade primária, o exemplo maior de esportividade biológica (ORTEGA Y GASSET, 1983b, p. 619), resultará na "exogamia", ou seja, na lei primeira matrimonial que obriga a buscar uma esposa fora dos membros consanguíneos (ORTEGA Y GASSET, 1983b, p. 618). O roubo, o rapto, teria sido a primeira forma de matrimônio, cujos resíduos arcaicos e sinais simbólicos permaneceriam até 0 presente em muitas cerimônias conjugais, e até mesmo no vocábulo amoroso "arrebatado" frequentemente empregado entre nós com esse fim -, que não quer dizer outra coisa do que tirado com violência, "raptado". (ORTEGA Y GASSET, 1983b, p. 618).
} 
distintas civilizações, se devem ao que os homens realizam de forma espontânea e sem um fim utilitário imediato.

Esse elemento talvez seja mais bem compreendido ao nos aproximarmos das reflexões de Ortega sobre a gênese da técnica, presentes no livro Meditación de la técnica. ${ }^{9}$ Ao se perguntar "o que é a técnica?", Ortega dirá que ela não pode ser compreendida apenas em sentido estritamente utilitário, como esforço do homem por estar no mundo, buscando satisfazer suas necessidades de alimentação, de abrigo, de aquecimento etc. Sua origem não poderia ser reduzida ao empenho para a satisfação de um conjunto de necessidades hierarquizadas que poderíamos denominar, inadequadamente, de vitais ou primárias. Tão antigas como os inventos de procedimentos técnicos para a satisfação de tais necessidades são tantas outras cuja finalidade consiste em proporcionar ao homem coisas e situações desnecessárias (ORTEGA Y GASSET, 1997, p. 32). "Frente a la construcción de máquinas, al cultivo del campo, etc.", diz Ortega, "se halla creación de cuadros, columnas, instrumentos musicales, bellos atavíos y lo que pertenece a la arquitectura; arte, precisamente, de la construcción. Hallamos ante nosotros, pues, tanto los utensilios técnicos como los enseres artísticos." (ORTEGA Y GASSET, 1997, p. 101). Alimentação, abrigo, aquecimento entre tantas necessidades, são naturalmente condições para viver, mas não o são em absoluto ou incondicionalmente. Elas são objetiva e materialmente necessidades somente na medida em que estão relacionadas ao viver:

el hombre reconoce esta necesidad [de alimentar-se, por exemplo] material u objetiva y porque la reconoce la siente subjetivamente como necesidad. No es, pues, el alimentarse necesario por sí, es necesario para vivir. Tendrá, pues, tanto de necesidad cuanto sea necesario vivir, si se ha de vivir. Este vivir es, pues, la necesidad originaria de que todas las demás son meras consecuencias" (ORTEGA Y GASSET, 1997, p. 24).

De acordo com a interpretação ortegueana, o empenho do homem não é para sobreviver, para estar no mundo, senão que para estar bem no mundo. Seu esforço não é apenas para viver, mas para viver bem (ORTEGA Y GASSET, 1997,

\footnotetext{
9 As referências dessa obra de Ortega y Gasset (1997) realizadas no presente trabalho correspondem ao volume 21 das Obras de Ortega y Gasset - Meditación de la técnica y otros ensayos sobre ciencia y filosofia -, editadas por Paulino Garagorri e publicadas pela Revista de Occidente en Alianza Editorial. A edição do volume utilizado data de 1997 (4⿻ reimpressão), sendo a sua primeira edição publicada em 1982. Uma tradução para o português do conjunto de aulas que compõem Meditación de la técnica pode ser consultada em Ortega y Gasset (1963).
}

p. 43). Só é necessário aquilo que torna possível o bem-estar do homem:

por tanto, para el hombre sólo es necesario lo objetivamente superfluo. [...] Las necesidades biológicamente objetivas no son, por sí, necesidades para él. [...] Sólo se convierten en necesidades cuando aparecen como condiciones del "estar en el mundo", que, a su vez, sólo es necesario en forma subjetiva; a saber, porque hace posible el "bienestar en el mundo" y la superfluidad. De donde resulta que hasta lo que es objetivamente necesario sólo lo es para el hombre cuando es referido a la superfluidad. No tiene duda: el hombre es un animal para el cual sólo lo superfluo es necesario. (ORTEGA Y GASSET, 1997, p. 3435; grifos nossos).

Elemento determinante no processo de hominização, a técnica é o que permite ao humano escapar das imposições de uma vida natural, presa estritamente à satisfação das carências materiais. Ela aparece, então, como produtora do que é supérfluo, de tudo quanto incrementa o bem-estar, enquanto um "esfuerzo para ahorrar el esfuerzo o, dicho en otra forma, es lo que hacemos para evitar por completo, o en parte, los quehaceres que la circunstancia primariamente nos impone." (ORTEGA $Y$ GASSET, 1997, p. 42).

Desse modo, o humano pode dedicar o esforço economizado a "que fazeres" não biológicos, podendo ocupar-se com a dimensão da vida que, na opinião de Ortega, mais interessa: que é aquela especificamente humana, de caráter extranatural, ${ }^{10}$ que, por mais que dependa da natureza e nela esteja inserido - ou seja, na rede de dificuldades e facilidades imposta pela circunstância (ORTEGA Y GASSET, 1997, p. 2627) -, não se confunde com ela e está ainda por fazer, constituindo-se como mera possibilidade de vir a ser. ${ }^{11}$ Isso porque, a natureza condiciona, mas não determina a realização da vida humana:

Zoologicamente, vida significa todo lo que hay que hacer para sostenerse en la naturaleza.

10 O ser do homem e o ser do mundo (da natureza) não coincidem plenamente, de forma que não é possível àquele sentir o ambiente exterior como idêntico a si: o homem não é, como o é o animal, um ser natural. Por outro lado, seu ser não é totalmente antagônico ao ser do mundo. O humano é, como define Ortega, uma espécie de centauro ontológico (ORTEGA Y GASSET, 1997, p. 46-47), uma vez que possui a estranha condição de que em parte seu ser é afim com a natureza e em parte não. Ele é, a um só tempo, assim como a figura mítica, parte natural - porção que está imersa na natureza e que se realiza por si mesma - e parte extranatural. Essa porção que transcende a natureza não lhe é dada, realizada; consiste antes numa mera pretensão de ser, em um projeto de vida.

${ }^{11}$ A vida humana, diz explícitamente Ortega, é um programa, um projeto, portanto, algo que ainda não é, mas aspira ser: "Eso que llaman su vida no es sino el afán de realizar un determinado proyecto o programa de existencia." (ORTEGA Y GASSET, 1997, p. 48). O homem é "un ente cuyo ser consiste no en lo que ya es sino lo que aún no es, un ser que consiste en aún no ser." (ORTEGA Y GASSET, 1997, p. 48). 
Pero el hombre se las arregla para reducir al mínimum esa vida, para no tener que hacer lo que tiene el animal. En el hueco que la superación de su vida animal deja, vaca el hombre a una serie de quehaceres no biológicos, que no le son impuestos por la naturaleza, que él se inventa a sí mismo. Y lo precisamente a esa vida inventada, inventada como se inventa una novela o una obra de teatro, es a lo que el hombre llama vida humana, bienestar. (ORTEGA Y GASSET, 1997, p. 43).

O esporte, entendido enquanto atividade desinteressada e expressiva, é a insígnia máxima desse espírito "abnegado" do humano, modelo do sentido festivo da vida humana, para a qual "lo más necesario es lo supérfluo." (ORTEGA Y GASSET, 1983b, p. 611).

Esse caráter modelar para significar a vida que o esporte adquire em Ortega é enfatizado em outros momentos de sua obra. Destaque, nesse contexto, para o curso intitulado ¿Que es filosofía?, pronunciado em 1926 na cidade de Madri, no qual o elogio e a valorização da atividade filosófica estão vinculados, assim como seria para todas as grandes obras humanas, à dimensão esportiva da vida, e na medida em que a filosofia conserva do esporte o "humor limpo" (limpio humor) e o "cuidado rigoroso" (ORTEGA Y GASSET, 1983e, p. 345), sua índole seria jovial. É o que podemos ler claramente na sexta lição do curso:

la cultura brota y vive, florece y fructifica en temple espiritual bien humorado - en la jovialidad. La seriedad vendrá después, cuando hayamos logrado la cultura o la forma de ella a que nos referimos - así, ahora, la filosofía. Mas, por lo pronto, jovialidad. Después de todo no es estado de ánimo que pueda parecer menospreciable; recuerden ustedes que la jovialidad no es sino el estado de ánimo en que suele estar Jove - Júpiter. Al educar en nosotros la jovialidad lo hacemos en imitación de Jove olímpico. (ORTEGA Y GASSET, 1983e, p. 348).

A filosofia, que é "la ciencia de los deportistas" (ORTEGA Y GASSET, 1983e, p. 330), não nasce por razões de utilidade. Tampouco, porém, sua origem seria sem motivo ou apenas um capricho. Ela responde, não exatamente como a ciência, preocupada diretamente com questionamentos e problemas de ordem prática (ORTEGA Y GASSET, 1983e, p. 323), à "necessidade" vital do humano, esse ser enfermo e desnorteado na natureza caótica, de buscar não apenas orientação, mas especialmente um sentido, uma perspectiva integral, um "sistema" cardeal de referência, como vimos Ortega definir há pouco sua reconstrução mitológica da origem do Estado. A filosofia, como expressão essencial do homo theoreticus, o qual tem como característica determinante o "don de convertir las cosas en problemas, en descubrir su latente tragedia ontológica" (ORTEGA Y GASSET, 1983e, p. 323), procura capturar o Universo, "caçar o Unicórnio" (ORTEGA Y GASSET, 1983e, p. 330). ${ }^{12}$ Por isso, Ortega dirá que

hay dentro del hombre biológico y utilitario otro hombre lujoso e deportivo, que en vez de facilitarse la vida aprovechando lo real, se la complica suplantando el tranquilo ser del mundo por el inquieto ser de los problemas. Esta raíz o dimensión teorética del ser humano es uno hecho último que hallamos el cosmos y que es vano querer explicar como consecuencia del principio utilitario, usado para comprender casi todos los otros fenómenos de nuestro organismo viviente. (ORTEGA Y GASSET, 1983e, p. 323).

Do ponto de vista de sua estrutura mais íntima, a filosofia corresponderia a um jogo, mais precisamente a um "jogo de ideias" (ORTEGA Y GASSET, 1983f, p. 305), e por isso, na Grécia clássica, onde ela nasceu, "después del traumatismo ocasionado por su descubrimiento en los pre-socráticos, instala definitivamente su modo de decir en un estilo risueño y al certamen y la competencia agonal. Como se juega al disco y al pancracio, se juega a filosofar." (ORTEGA Y GASSET, 1983f, p. 305).

Como se vê, Ortega parece estar preocupado em demarcar o caráter não utilitarista da filosofia, questionando a sua subordinação à ação, à dimensão prática da vida humana. Encontramos novamente nessa assertiva aquele tema caro à antropologia filosófica de Ortega, anteriormente referido: o entendimento de que todas as grandes realizações humanas - a cultura, a filosofia, a sociedade, e até mesmo a técnica - são produtos não da carência, da necessidade e do embate violento contra a natureza, em uma palavra, expressões do sofrimento humano, mas sim do esforço do homem para produzir aquilo que é supérfluo, que é, para Ortega, o verdadeiramente "indispensável" para que o humano não apenas viva, mas para que viva bem e feliz sobre este mundo. As atividades supérfluas, tal como as lúdico-expressivas - entre as quais destaca-se especialmente 0 esporte - , seriam aquelas realmente fundantes da atividade humana, cuja atitude de gratuidade, de espontaneidade, de

\footnotetext{
12 Ortega pergunta-se por que esse afã humano em buscar o todo e, portanto, de filosofar, se poderíamos simplesmente nos contentar com o que encontramos no mundo sem a filosofia, com aquilo que já é, que está aí patente ante nós. A razão disso seria que "todo lo que es y esta ahí, cuanto nos es dado, presente, patente, es por su esencia mero trozo, pedazo, fragmento, muñón. $Y$ no podemos verlo sin prever $y$ echar de menos la porción que falta. En todo ser dado, en todo dato del mundo encontramos su esencial línea de fractura, su carácter de parte y sólo parte - vemos la herida de su mutilación ontológica, nos grita su dolor de amputado, su nostalgia del trozo que le falta pare ser completo, su divino descontento." (ORTEGA Y GASSET, 1983e, p. 330).
} 
jovialidade seria muito mais "genuinamente humana" do que a dor e a consternação resultantes do embate com a natureza: " $Y$ todo ello con calma jovial - un temple tan 'existencial' como puedan serlo iracundias, acedías y angustias [...]." (ORTEGA Y GASSET, 1983e, p. 23).

Trata-se, em última instância, da dimensão luxuosa e esportiva da vida que, em seu íntimo afã de felicidade, seria uma espécie de núcleo gerador não apenas do agir técnico, na medida em que o coloca a serviço da dignidade da vida, mas de toda a empresa humana, o que inclui a cultura, os jogos, a sociedade, a política, 0 pensamento e a forma mais expressiva deste, a filosofia.

\section{Esporte, técnica e aristocracia}

O significado metafórico do esporte na obra de Ortega - assim como também o problema da técnica, que, como vimos, tem íntima relação com aquele, uma vez que ambos nascem não da premência, do desassossego e da agonia, mas da ludicidade e do caráter festivo da vida humana está diretamente associado à importância atribuída pelo autor àquela dimensão da existência que poderíamos denominar, a partir do próprio Ortega, de aristocrática. Dois momentos de sua obra do autor de maneira emblemática essa valorização.

O primeiro, extraído do livro $A$ rebelião das massas, expõe a interpretação da história e da sociedade sustentada por Ortega, a qual, segundo seus próprios termos, é radicalmente aristocrática (ORTEGA Y GASSET, 1983d, p. 150). É radical, explica o autor, porque na sua opinião a sociedade - mas não o Estado -deve não apenas ser aristocrática, senão que ela é, na sua essência mesma, sempre aristocrática ${ }^{13}$, uma vez que, segundo afirma, ela é sociedade

\footnotetext{
13 Em outro momento de sua obra, Ortega assinala de maneira bastante eloquente essa radicalidade aristocrática da sociedade, destacando, inclusive, a relação quase orgânica que existiria entre esporte e aristocracia: "No se debe olvidar nunca, si se quiere llegar a una idea clara sobre las fuerzas radicales productoras de sociabilización, el hecho, cada vez más comprobado, de que las asociaciones primarias no fueran de carácter político y económico. El Poder, con sus medios violentos, y la utilidad, con su mecanismo de intereses, no han podido engendrar sociedades sino dentro de un asociación previa. Estas primigenias sociedades tuvieran un carácter festival, deportivo o religioso. La ejemplaridad estética, mágica o simplemente vital de unos pocos atrajo a los dóciles. Todo otro influjo o cracia de un hombre sobre los demás que no sea automática emoción suscitada por el arquetipo o ejemplar en los entusiasmos que le rodean, son efímeros y secundarios. No hay, ni ha habido jamás, otra aristocracia que la fundada en ese poder de atracción psíquica, especie de ley de gravitación espiritual que arrastra a los dóciles en pos de un modelo." (ORTEGA Y GASSET, 1983c, p. 105).
}

enquanto se mantém aristocrática, e deixa de sêlo na medida em que se "desaristocratiza" (ORTEGA Y GASSET, 1983d, p. 150). Sociedade e aristocracia seriam, para Ortega, termos equivalentes, sinônimos. A aristocracia social, a "verdadeira" aristocracia, adverte Ortega, é algo bem distinto do que um grupo de pessoas que se autodenomina de "sociedade", de "alta sociedade", e que vive de festas e pompas. Também é algo diverso do que fora a frivolidade da Corte de Versailles. Esta, aliás, representa para Ortega o oposto do que seja a aristocracia: "es la muerte y la putrefacción de una magnífica aristocracia." (ORTEGA Y GASSET, 1983d, p. 150). Essa "aristocracia magnífica" tem em suas mãos, como uma obrigação moral enquanto minoria dirigente, diz o autor, um papel destacado no comando e no destino de nossa sociedade. Trata-se de sua missão de exemplaridade: a ela compete, por conta de sua disciplina, de seu senso de obrigação e de sua responsabilidade intelectual - que diferentemente do homem médio, o qual não se coloca nenhuma exigência especial, demanda muito de si mesma e se acumula de problemas e deveres -, conceber programas vitais coletivos tanto para si quanto para a maioria ${ }^{14}$, para a massa: "a quien sienta la misión profunda de las aristocracias, el espectáculo de la masa le incita y enardece como al escultor la presencia del mármol virgen." (ORTEGA Y GASSET, 1983d, p. 150).

O segundo momento da obra de Ortega ao qual mencionamos acima, cuja relação é íntima com o primeiro e representa uma espécie de ponto de intersecção entre as temáticas do esporte, da vida aristocrática e da técnica, ocorre, não por acaso, no livro Meditación de la técnica, anteriormente referido.

A vinculação entre técnica e esporte com a problemática da aristocracia aparece de maneira marcante no sexto capítulo do livro em questão (ORTEGA Y GASSET, 1997, p. 63-66), quando Ortega, ao discutir o lugar da técnica na extranaturalidade dos projetos vitais humanos, toma como objeto de análise e exemplo duas concepções de homem historicamente concretizadas. Com esse objetivo, o autor opõe a

\footnotetext{
${ }^{14}$ Embora não tenhamos condições de aprofundar este tema no presente trabalho, importa destacar que Ortega estabelece uma diferenciação, que considera mais radical e, portanto, mais abrangente e anterior àquela entre idade e sexo, da qual emerge duas classes de criaturas humanas: a dos que são disciplinados, possuem qualificações especiais e que se enchem de deveres para com a civilização e a cultura - as minorias excepcionais; e a dos que se abandonam a si próprios, que são medíocres, sem qualificação especial, e que não estão dispostos a realizar esforços para progredirem - a maioria, a massa. Às primeiras cabe "pensar" e "mandar" e às segundas "ouvir" e "obedecer".
} 
situação do homem quando é, como projeto, bodhisatva (termo budista que designa seres de sabedoria elevada), com a do que se propõem a ser gentleman. A contraposição entre esses dois "tipos" humanos, dada, fundamentalmente, pelas diferenças de seus projetos vitais $e$, consequentemente, pelo desenvolvimento do tipo de técnica (de alimentação, locomoção, abrigo etc.) correspondente a cada um, está vinculada, para Ortega, aos esforços que cada um empreende para viver. Enquanto o primeiro se esforça para se fundir ao Todo e nele desaparecer, para não viver ou viver o menos intensamente possível, ou seja, a verdadeira existência para ele consistiria em não-ser, em não tornar-se indivíduo, o segundo emprega toda sua vitalidade para "vivir con intensidad en este mundo y ser lo más individuo que pueda, centrarse en sí mismo y nutrirse de una sensación de independencia frente a todo." (ORTEGA $Y$ GASSET, 1997, p. 65). O mais importante, considerando a relação entre esporte, técnica e aristocracia, se encontra, no entanto, no tipo de esforço, de empenho em viver, valorizado por Ortega, que, não sem motivo, é idealizado e concretizado historicamente pelos aristocratas ingleses e que constitui a grande marca distintiva do gentleman, esse modo particular de ser homem.

É importante destacar que, embora Ortega afirme categoricamente que o gentleman inglês não é um aristocrata (ORTEGA Y GASSET, 1997, p. 61), o fato é que essa afirmação precisa ser relativizada na medida em que está relacionada à distinção que o autor faz, tendo como referência geográfica o continente europeu, entre aristocracia continental e aristocracia inglesa, diferenciação outras vezes mencionada - embora não exatamente com essas denominações -, e que é recorrente em sua obra. A primeira forma de aristocracia, que Ortega nomeia também de herdeira $^{15}$, e a qual não vê com bons olhos, legou de seus antepassados o prestígio e a riqueza financeira e cultural sem que tivesse que lutar, tanto material quanto espiritualmente, para conquistá-la. Além disso, acrescenta o autor, esses nobres são fechados em classes, e igualmente cerrados em relação ao tipo de ocupação a que se dignavam dedicar: guerra, política, diplomacia, esporte, alta direção de economia agrícola (ORTEGA Y GASSET, 1997, p. 61). Diferentemente, o aristocrata inglês ${ }^{16}-\mathrm{e}$

\footnotetext{
15 Sobre as críticas que Ortega desfere contra a forma hereditária de aristocracia, conferir especialmente o capítulo VII de $A$ rebelião das massas (ORTEGA Y GASSET, 1983d, p. 180-185).

${ }^{16}$ Ortega rende frequentes elogios aos ingleses. Conferir, por exemplo, o Epílogo para ingleses de $A$ rebelião das massas
}

esse termo é do próprio Ortega (ORTEGA Y GASSET, 1997, p. 61) -, que não é um herdeiro, aceitaria, desde o século $\mathrm{XVI}$, a tarefa de lutar pela sua vida, considerando como "campo de batalha" válido o terreno econômico do comércio, da indústria e das carreiras liberais. Esta é, para Ortega, a marca distintiva e também valorativa entre uma e outra forma de aristocracia, ou seja, o fato de uma ser ativa, produtora e diretamente engajada na luta por sua existência. Ortega acaba estabelecendo uma dicotomia similar àquela do economista estadunidense Thorstein Veblen (1857-1929) no seu famoso livro $A$ teoria da classe ociosa, que diferencia duas classes, uma industrial e progressista e outra ociosa e usurpadora, empregando como critério igualmente a participação na esfera da economia, mais especificamente no âmbito da produção industrial (VEBLEN, 1987). Essa valorização por parte de Ortega da aristocracia inglesa não está vinculada exclusivamente a esse critério, mas também, e principalmente ao fato do gentleman inglês ser um jogador.

Mas que tipo de esforço vital é esse valorizado pelo filósofo madrilenho e que caracteriza de maneira positiva o tipo social gentleman? Ou ainda: o que é ser gentleman? Com a palavra, o próprio Ortega:

el comportamiento que el hombre suele adoptar durante breves momentos en que las penosidades y apremios de la vida dejan de abrumarle y se dedica, para distraerse, a un juego, aplicado al resto de la vida, es decir, a lo serio a lo penoso de la vida: eso es el gentleman. (ORTEGA Y GASSET, 1997, p. 63).

Essa conduta do gentleman, que vive toda a vida, e não apenas os momentos de "folga vital" (ORTEGA Y GASSET, 1997, p. 65), como se fosse um grande jogo, exemplifica, para Ortega, a extranaturalidade do que é vida para o ser humano, uma vez que os jogos e os modos de comportamento que deles resultam são invenções genuínas diante do tipo de vida que a natureza dá para o homem. Nesse sentido, diz Ortega, percebe-se que "aun dentro de la vida humana misma, se invierten los términos y se propone que el hombre sea en su existencia forzada, de lucha con el medio, según es en el rincón irreal y puramente inventado de sus juegos y deportes." (ORTEGA Y GASSET, 1997, p. 63).

No entanto, esse caráter lúdico ou esportivo com o qual o gentleman encara a vida não está

(ORTEGA Y GASSET, 1983d, p. 281-285), bem como a passagem, também presente no livro em questão, na qual destaca o papel simbólico da monarquia inglesa (ORTEGA Y GASSET, 1983d, p. 137), qual seja, o de conservação do passado e das regras que regulam a vida. Nesse sentido, a Inglaterra seria um exemplo, como uma espécie de "enfermeira" em relação à Europa continental "adoentada". 
isento de esforço. Porém, na medida em que ele não é provocado pelo utilitarismo mais raso que inspira o esforço imposto pelo trabalho, está assentado em si mesmo sem o desassossego característico daquele, o qual incute no esforço laboral a necessidade de alcançar, a qualquer custo, o seu fim (ORTEGA Y GASSET, 1997, p. 64). Diante dessa característica, o gentleman se satisfaz com sua própria condição e se dá ao luxo - porque o jogo é um luxo vital, diz Ortega (ORTEGA Y GASSET, 1997, p. 63) - de jogar limpo, exercer o fair play, que tem como predicado, segundo Ortega, a justiça, ou seja, "de defender sus derechos, pero respetando los del prójimo, de no mentir. Mentir en el juego es falsificar el juego y, por tanto, no jugar." (ORTEGA Y GASSET, 1997, p. 64). Também em função da qualidade diferenciada desse esforço "prazeroso" que marcaria a vida do aristocrata inglês, emergiriam as maneiras de ser do gentleman:

Su espíritu de justicia, su veracidad, el pleno dominio de sí fundado en el previo dominio de lo que le rodea, la clara conciencia de lo que es su derecho personal frente a los demás y del de los demás frente a él; es decir, de sus deberes. Para él no tiene sentido la trampa. Lo que se hace hay que hacerlo bien y no preocuparse de más. (ORTEGA Y GASSET, 1997, p. 64).

$A$ vinculação entre o gentleman, expressão máxima da vida aristocrática, e os temas do esporte e da técnica, emerge também do fato daquele só poder ser um "jogador" na medida em que está suposto seu prévio e pleno domínio sobre as zonas inferiores da existência. O elemento principal, conforme aponta Ortega, no qual reside a atmosfera do gentleman, é a anteriormente mencionada folga vital, que não quer dizer outra coisa do que "dominio superabundante sobre la circunstancia." (ORTEGA Y GASSET, 1997, p. 65). "Por eso", afirma o filósofo espanhol, "este hombre que aspira a hacer de la existencia un juego y un deporte es lo contrario de un iluso; precisamente porque quiere eso sabe que la vida es cosa dura, seria y difícil." (ORTEGA Y GASSET, 1997, p. 65). Ele sabe que a "gentlemanerie" não pode florescer sem que exerça um duplo e implacável domínio: sobre a natureza (domínio técnico) e sobre a massa (dominação política), a maioria, no sentido específico dado pelo autor no livro $A$ rebelião das massas (ORTEGA Y GASSET, 1983d, p. 112-285; ORTEGA Y GASSET, 2002). Nas palavras de Ortega: "por ello [el gentleman] se ocupará a fondo en asegurarse ese dominio sobre la circunstancia - dominio sobre la materia - y sobre los hombres. De aquí que haya sido el gran técnico y el gran político." (ORTEGA Y GASSET, 1997, p. 65).
Esse modus vivendi, esse fair play, estaria presente, segundo afirma Ortega, em todas as dimensões da vida da aristocracia inglesa, desde a política, passando pela economia e chegando até os hábitos e cuidados pessoais, principalmente aqueles com o próprio corpo. Estes últimos, aliás, são especialmente sublinhados por Ortega, que destaca como um aspecto positivo o fato do gentleman destinar, "com grande formalidade", cuidados com a higiene e aparência de seu "corpo enobrecido". O gentleman "busca o decorum en toda su vida: alma limpia y cuerpo limpio." (ORTEGA Y GASSET, 1997, p. 65). Portanto, o culto do corpo é acrescentado, no caso do gentleman, também como expressão positiva do sentido festivo da vida, uma vez que seu afã de viver intensamente e de dar ao seu destino mundano a forma de um jogo, implica na imperiosa necessidade de se separar, se diferenciar dos demais e das coisas, algo somente possível, conforme deixa entrever Ortega, pelo rígido controle sobre a sua natureza interna, seu próprio corpo. Um dos pilares que sustenta a maneira de ser desse tipo social é justamente, como se assinalou anteriormente, o "pleno dominio de sí fundado en el previo dominio de lo que le rodea." (ORTEGA Y GASSET, 1997, p. 64).

\section{Corpo, juventude e esporte}

No entanto, não é apenas como metáfora, no sentido que acabamos de descrever, que Ortega se utiliza do esporte em seus trabalhos. À altura, como ele mesmo se declara, dos problemas prementes de seu tempo, também se dedicou a pensar e escrever sobre aquilo que viu como processo de vulgarização do esporte, sua transformação em espetáculo de massa. Vários escritos de Ortega enfatizam essa interpretação ${ }^{17}$, e, dentre eles, destaque especial para o conjunto de artigos intitulado Dinámica del tiempo, publicados inicialmente no periódico El Sol entre 15 de maio a 3 de julho de 1927 (ORTEGA Y GASSET, 1983c, p. 459-480). A importância desses artigos se faz notar pelo fato de que, tanto parcial quanto integralmente, ou mesmo sob a forma de apêndices, eles foram incorporados a outros trabalhos de Ortega, como é o caso da segunda, terceira e quarta conferências pronunciadas durante sua segunda visita a Argentina em 1928 - reunidas no livro Meditación de nuestro tiempo ${ }^{18}$-, e do livro La rebelión de las

\footnotetext{
17 Conferir, por exemplo: Revés de almanaque (ORTEGA Y GASSET, 1983b, p. 719-742) e El tema de nuestro tiempo (ORTEGA Y GASSET, 1983c, p. 187-203).

${ }^{8}$ O conjunto de conferências que Ortega pronunciou em Buenos Aires em 1916 e 1929 - Ortega esteve numa terceira oportunidade na Argentina, em 1939 - foi reunido no livro acima mencionado por José Luis Molienuevo, publicado pela
} 
masas (ORTEGA Y GASSET, 2005, p. 719749). ${ }^{19}$

Nesses ensaios, intitulados Los escaparates mandan (ORTEGA Y GASSET, 1983c, p. 459463), Juventud (ORTEGA Y GASSET, 1983c, p. 463-471), ¿Masculino o femenino? (ORTEGA Y GASSET, 1983c, p. 471-480), Ortega irá criticar a massificação do esporte, sobretudo dos esportes físicos, e, dentre eles, especialmente o futebol, como expressão do culto do corpo promovido pela juventude, ${ }^{20}$ a qual, de acordo com a sua particular interpretação sobre a dinâmica histórica, anteriormente referida, dominaria a sociedade de sua época:

Lo que sí me parece evidente es que nuestro tiempo se caracteriza por el extremo predominio de los jóvenes. Es sorprendente que en pueblos tan viejos como los nuestros [Ortega se refere à Europa] y después de una guerra más triste que heroica, tome la vida de pronto un cariz de triunfante juventud. En realidad, como tantas otras cosas, este imperio de los jóvenes venía preparándose desde 1890, desde el fin de siècle. Hoy de un sitio, mañana de otro, fueron desalojados la madurez y la ancianidad: en su puesto se instala el hombre joven con sus peculiares atributos. (ORTEGA Y GASSET, 1983c, p. 465).

Por um lado, como aspecto positivo do predomínio da juventude sobre as demais classes, constituídas pelos homens maduros (adultos) e pelos anciões, Ortega vê no entusiasmo pelo corpo que marca as primeiras três décadas do século $X X$ um resgate da

Fondo de Cultura Económica em 1996 (ORTEGA Y GASSET, 1996). A respeito das viagens de Ortega a Argentina e das conferências, cursos e seminários que ali realizou em 1916 e 1928, conferir a introdução de Molinuevo (1996) ao livro supracitado.

${ }^{19}$ Ortega incorporou integralmente, sob a forma de apêndice, o conjunto de ensaios Dinámica del tiempo ao livro em questão, escrito em 1930. Esse apêndice, no entanto, não figura como parte do livro no volume IV de suas Obras Completas, embora apareça em outras edições de La rebelión de las masas, como na de 2005 da Editora Espasa Calpe (ORTEGA Y GASSET, 2005, p. 453-750) e na edição brasileira do livro, publicada em 1987 (ORTEGA Y GASSET, 2002).

${ }^{20}$ De acordo com dinâmica do tempo predicada por Ortega, que, como vimos, é declaradamente de caráter biologicista, juventude e corpo são termos equivalentes, assim como espírito e maturidade também o são. Nas palavras do autor: "Cuando se piensa en la juventud se piensa ante todo en el cuerpo. Por varias razones; en primer lugar, el alma tiene un frescor más prolongado que a veces llega a ornar la vejez de la persona, y en segundo lugar, el alma es más perfecta en cierto momento de la madurez, que en la juventud. Sobre todo, el espiritu, inteligencia y voluntad es sin duda más vigoroso en la plena cima de la vida, que en su etapa ascensional. En cambio, el cuerpo tiene su hora de flor, su akmé, en la estricta juventud, $y$, viceversa, decae infaliblemente cuando ésta se traspone. Por eso, desde un punto de vista superior a las oscilaciones históricas por decirlo así, sub specie aeternitatis, es indudable que la juventud rinde la mayor delicia al ser mirada, y la madurez al ser escuchada. Lo admirable del mozo es su exterior; lo admirable del hombre hecho es su intimidad." (ORTEGA Y GASSET, 1996, p. 220). dimensão corporal, praticamente esquecida ao largo dos três séculos anteriores. Isso significaria, para o autor, uma verdadeira ressurreição da representação do corpo como carne - e não simplesmente como matéria ou substância, interpretação predominante na filosofia moderna ${ }^{21}$ - depois de um logo período de culto e preponderância do espírito. Mas, por outro, esse entusiasmo também representa, na excessiva importância que adquire na vida social, uma espécie de rebelião do corpo (ORTEGA Y GASSET, 1996, p. 224) que sufoca a importância e consequentemente a exemplaridade - no sentido específico que Ortega dá a esse conceito (ORTEGA Y GASSET, 1983c, p. 103-108) - das expressões características (como a arte, a ciência, a religião, a política) da vida espiritual do homem maduro que compõem as elites, as minorias. Nas palavras de Ortega:

Hoy se prefiere el cuerpo al espíritu. No creo que haya síntoma más importante en la europea actual. Tal vez las generaciones han rendido demasiado culto al espíritu y - salvo Inglaterra - han desdeñado excesivamente a la carne. Era conveniente que el ser humano fuese amonestado y se le recordase que no es sólo alma, sino unión de espíritu e cuerpo. El cuerpo es por sí puerilidad. El entusiasmo que hoy despierta ha inundado de infantilismo la vida continental, ha aflojado a tensión de intelecto y voluntad en que retorció el siglo XIX, arco demasiado tirante hacia metas demasiado problemáticas. (ORTEGA Y GASSET, 1983c, p. 470).

Essa rebelião do corpo é visível, segundo Ortega, não apenas no exorbitante crescimento da prática de esportes físicos - que provocaria, por consequência, a sua "desaristocratização" -, mas também na "epidemia" dos bailes e da dança, no triunfo das salas de cinema, na preocupação exagerada com a higiene, a aparência e a moda, que se faria presente em todas as classes, ou seja, entre homens e mulheres, entre jovens, adultos e velhos, entre minoria e massa. Em tom de crítica, o autor espanhol dirá que o fato das pessoas preferirem ouvir música e dançar esconde, na verdade, a falta de assuntos interessantes que caracterizaria suas falas (ORTEGA Y GASSET, 1996, p. 225226). Assim, diz Ortega, "las almas permanecen distantes mientras el jazz propone la proximidad de los cuerpos." (ORTEGA Y GASSET, 1996, p. 226).

O problema, para Ortega, encontra-se menos no gesto da juventude em cultuar o corpo, em praticar esportes, enfim, em entregar-se sem

\footnotetext{
${ }^{21}$ Sobre o tema conferir os ensaios de Ortega Vitalidad, alma, espíritu (ORTEGA Y GASSET, 1983b, p. 451-80) e Sobre la expresión fenómeno cósmico (ORTEGA Y GASSET, 1983b, p. 577-594)
} 
reservas a seu próprio momento, um estágio de sua vida, do que no excesso, na exorbitância desse culto, que acaba tornando a juventude cerrada, fechada em si mesma, rompendo assim todos os acessos que poderiam conduzi-la aos estágios subsequentes, o que representaria menos um ato voluntário de sublevação contra o domínio do modo de vida do homem adulto, de que declarar-se em rebeldia e separatismo contra a própria vida. Pois, conforme afirma,

[...] la vida, objetivamente, necesita de la madurez; por tanto, que la juventud también la necesita. Es preciso organizar la existencia: ciencia, técnica, riqueza, saber vital, creaciones de todo orden, son requeridas para que la juventud pueda alojarse y divertirse. La juventud de ahora, tan gloriosa, corre el riesgo de arribar a una madurez inepta. Hoy goza el ocio floreciente que le han creado generaciones sin juventud. Mi entusiasmo por el cariz juvenil que la vida ha adoptado no se detiene más que ante este temor. ¿Qué van a hacer a los cuarenta años los europeos futbolistas? Porque el mundo es ciertamente un balón, pero con algo más que aire dentro. (ORTEGA Y GASSET, 1983c, p. 471).

Nesse sentido, Ortega pergunta-se porque os adultos maduros e os anciões, portanto, homens de espírito, não conseguiram no "tempo presente" se contrapor à rebelião do corpo e da juventude. A resposta reside no fato de que os jovens, de maneira análoga ao homem-massa - objeto de análise e dissecação naquele que é, provavelmente, o livro mais conhecido e importante de Ortega, $A$ rebelião das massas (ORTEGA Y GASSET, 1983d, p. 112-285; ORTEGA Y GASSET, 2002) - , autocentrados e isolados em si, não desejam ouvir as gerações mais velhas e nem se deixar guiar por elas, assim como aquele, que de forma indócil2 e sem reconhecer o seu devido lugar (ORTEGA Y GASSET, 1983d, p. 184), também não ouve e não se deixa influenciar pela exemplaridade da minoria aristocrática:

En este tono primitivo de las almas nuevas vienen a mezclarse algunos de los rasgos que yo he apuntado en las conferencias anteriores [Ortega se refere às conferências pronunciadas na Argentina]: la exaltación del hombre masa, la juventud y del entusiasmo por el cuerpo. Todos ellos son rasgos que suponen una urgencia de simplificación. Los actos corporales son más sencillos que el del espíritu, están hechos de una manera más clara y dominable. Por eso las muchedumbres se desinteresan del arte y van a conmoverse en el brinco certero de un futbolista. El espíritu parece abandonado. Sus ingentes proyectos y sus vastas utopías ya no producen incandescencias en los corazones y

\footnotetext{
${ }^{22}$ Sobre o conceito de docilidade das massas e sua relação com o de exemplaridade da aristocracia, conferir o quinto capítulo do livro España invertebrada (ORTEGA Y GASSET, 1983c, p. 103-108).
}

los hombres nuevos de espaldas a todo, se ponen a jugar. (ORTEGA Y GASSET, 1996, p. 278).

\section{Conclusão}

Se, por um lado, as referências ao esporte aparecem na obra de Ortega y Gasset sob a forma de notas esparsas e comentários ocasionais, por outro, é preciso considerar que a importância do tema parece ser significativamente maior do que o lugar por ele ocupado em termos quantitativos. Isso porque, conforme se procurou mostrar, a compreensão de Ortega sobre o esporte está diretamente vinculada às questões que compõem o núcleo central de suas reflexões filosóficas.

Nesse sentido é que o esporte pode ser lido no contexto da obra do autor como uma espécie de metáfora significadora do caráter jovial, aberto, luxuoso, lúdico e não-utilitarista da vida humana, da vida de cada um, entendida enquanto projeto extranatural concebido e fabricado pelo homem. De maneira mais precisa, Ortega toma o esporte e mais especificamente o "espírito esportivo", na sua articulação com a problemática da técnica, como demonstrado anteriormente, em contraposição à necessidade e à obrigação, como símbolo do desejo e da capacidade criadora do homem, como paradigma do estado anímico e da forma como ele, espontânea, criativa e inventivamente, encara a vida.

Também são dignas de nota as pioneiras e argutas análises de Ortega sobre o nascente processo de expansão do esporte e sua crescente importância social nas primeiras décadas do século $X X$, expostas em nossa terceira categoria. Nessas análises, o fenômeno esportivo comparece articulado ao problema do culto do corpo - presente também nas análises que Ortega faz do gentleman como expressão máxima da vida aristocrática, conforme mostrado em nossa segunda categoria - e da "rebelião" da juventude. Aliás, as reflexões de Ortega sobre a juventude também constituem pioneirismo, pois o autor, já no primeiro terço do século passado, chama a atenção para a necessidade de considerar aquilo que denominamos contemporaneamente de cultura(s) juvenil(s) como uma problemática filosófica e sociológica.

Nessas análises sobre o fenômeno esportivo há também uma estreita vinculação com as questões caras ao escopo de preocupações do filósofo espanhol, uma vez que, como se mostrou anteriormente, a massificação do esporte, o culto do corpo e da juventude, assim como o problema da emergência das multidões, fatos marcantes nas primeiras décadas do século $X X$, são 
fenômenos que, para Ortega, se inscrevem no mesmo nexo, qual seja, o da "desaristocratização" da sociedade e da cultura.

\section{Referências}

ADORNO, T. W. Veblens angriff auf die kultur. In: . Gesammelte Schriften 10-1. Frankfurt am Main: Suhrkamp, 1997, p. 72-96.

BOLAÑO, T. Sport is vital luxury and philosophy the science of sportsmen in Ortegiana Metaphysic. Lecturas, Educación Física y

Deportes: revista digital, Buenos Aires, año 13, n. 121, jun. 2008. Disponível em:

$<$ http://www.efdeportes.com/efd121/sportphilosophy-in-ortegiana-metaphysic.htm>. Acesso em: 17 jun. 2011.

DAMATTA, R. Esporte na sociedade: um ensaio sobre o futebol brasileiro. In: (Org.).

Universo do futebol: esporte e sociedade brasileira. Rio de Janeiro: Pinakotheke, 1982. p. 19-42.

HABERMAS, J. Soziologische notizen zum verhältnis von arbeit und freizeit. In: PLESSNER, H.; BOCK, H. E.; GRUPPE, O. Sport und Leibeserziehung. München: Piper \& Co, 1967. p. 28-46.

MOLINUEVO, J. L. Introducción. In: ORTEGA y GASSET, J. Meditacíon de nuestro tiempo: las conferencias de Buenos Aires, 1916 y 1928. Madrid: Fundo de Cultura Econômica, 1996. p. 732.

MORA, J. F. Ortega y Gasset: etapas de una filosofia. Barcelona: Seix Barral, 1973.

ORTEGA Y GASSET, J. Meditação da técnica. Rio de Janeiro: Ibero-Americano, 1963.

ORTEGA Y GASSET, J. Obras completas. Madrid: Alianza Editorial/Revista de Occidente, 1983a. 12v.

ORTEGA Y GASSET, J. Obras completas. Madrid: Alianza Editorial: Revista de Occidente, 1983b. v. 2.

ORTEGA Y GASSET, J. Obras completas. Madrid: Alianza Editorial: Revista de Occidente, 1983c. v. 3.

ORTEGA Y GASSET, J. Obras completas. Madrid: Alianza Editorial/Revista de Occidente, 1983d. v. 4.

ORTEGA Y GASSET, J. Obras completas. Madrid: Alianza Editorial/Revista de Occidente, 1983e. v. 7.
ORTEGA Y GASSET, J. Obras completas. Madrid: Alianza Editorial/Revista de Occidente, 1983f. v. 8.

ORTEGA Y GASSET, J. Meditacíon de nuestro tiempo: las conferencias de Buenos Aires, 1916 y 1928. Madrid: Fundo de Cultura Econômica, 1996.

ORTEGA Y GASSET, J. Meditacion de la técnica y otros ensayos sobre ciencia y filosofia. Madrid: Revista de Occidente en Alianza Editorial, 1997.

ORTEGA Y GASSET, J. A rebelião das massas. 2. ed. São Paulo: Martins Fontes, 2002.

ORTEGA Y GASSET, J. Obras selectas. Madrid: Espasa Calpe, 2005.

SPENGLER, O. A decadência do ocidente: esboço de uma morfologia da História Universal. 2. ed. Rio de Janeiro: Zahar Editores, 1973

\section{SPENGLER, O. Der untergang des} abendlandes: umrisse einer morphologie der weltgeschichte. Düsseldorf: Albatros, 2007.

VEBLEN, T. A teoria da classe ociosa: um estudo econômico das instituições. 2. ed. São Paulo: Nova Cultural, 1987.

Apoio: CAPES (Bolsa de Doutoramento) e do CNPq (Processos n. 572119/2008-9, 502892/2008-0, 308912/2007-1, 503353/2007-8).

\section{Endereço:}

Jaison José Bassani

DEF/CDS/UFSC - Campus Univ. da Trindade Florianópolis SC Brasil - Caixa Postal 476 88040-900

Telefone: (48) 3721.9462 Fax: (48) 3721.9368

e-mail: jaisonbassani@uol.com.br

Recebido em: 19 de maio de 2010.

Aceito em: 20 de julho de 2011.

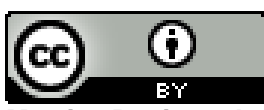

Motriz. Revista de Educação Física. UNESP, Rio Claro, SP, Brasil - elSSN: 1980-6574 - está licenciada sob Creative Commons - Atribuicão 3.0 